Article

\title{
A Collaborative Action Research about Making Self-Advocacy Videos with People with Intellectual Disabilities
}

\author{
Ann-Louise Davidson \\ Department of Education, Concordia University, Montreal, H3H 2S2, Canada; \\ E-Mail: ann-louise@education.concordia.ca
}

Submitted: 31 July 2015 | In Revised Form: 30 November 2015 | Accepted: 17 December 2015 |

Published: 28 December 2015

\begin{abstract}
This article presents the results of a collaborative action research conducted with people living with intellectual disabilities (ID) who were going through a community integration process. To be successfully integrated into a community, they need to develop basic life skills as much as they need to learn to use mobile technologies for authentic interactions (Davidson, 2012) and to be self-advocates online (Davidson, 2009a). This study used the Capability Approach pioneered by Sen (1992) and Nussbaum (2000), which focusses on what people can do rather than on their deficiencies. I recruited a group of eight people with ID who wished to set goals, engage in developing new capabilities, share their goals and act as models for others with ID who want to learn to live on their own. In this article, I examine the process of developing self-advocacy videos with mobile technologies using the Capability Approach and I analyze the inventory of capabilities collected through this study. I provide recommendations for intervention through mobile technologies with the long term-goal of helping people with ID to become contributing citizens. I discuss the innovative action research methodology I used to help people with ID become self-advocates and take control of the messages they give through producing their own digital resources.
\end{abstract}

\section{Keywords}

Capability Approach; collaborative action research; community integration process; intellectual disability; mobile technology; self-advocacy videos

\section{Issue}

This article is part of the special issue "Inclusive Technologies and Learning", edited by Don Passey (Department of Educational Research, Lancaster University, UK).

(C) 2015 by the author; licensee Cogitatio (Lisbon, Portugal). This article is licensed under a Creative Commons Attribution 4.0 International License (CC BY).

\section{Introduction}

People with intellectual disabilities (ID) have always faced substantial daily challenges. Some of these challenges are related to the labeling of their condition, which is attributed to them by the very science that should serve them. People with ID live with their label and it takes over their lives, but very often they don't understand why they have been attributed this label (Davidson, 2009a). Other challenges are related to their difficulty with being autonomous, taking daily life responsibilities and making decisions for themselves (Brown \& Percy, 2007). This is partly why, traditionally, people with ID were placed in institutions. Unfortunately, in these institutions, many were abused (Boulanger, Wieszmann, \& Wolbert, 2010).

The United Nations Convention on the Rights of Persons with Disabilities (United Nations, 2006) marked an international paradigm shift in terms of how people with various disabilities should be treated with equality and included as fully-fledged members of society. At present, this convention is challenging for Asian, African and Latin American countries, because "there is no clear plan for improving the condition of the population with ID, though some aspects such as education have been recently addressed by a number 
of countries" (Memari \& Hafizi, 2015, p. 39). Some countries, such as Canada, have been at the forefront of inclusive policies with regards to the human rights of people with ID by ratifying the United Nations Convention on the Rights of Persons with Disabilities and by taking steps towards inclusive practices and better services for people with ID among other populations traditionally excluded from equal social participation (Canadian Association for Community Living, 2011; Council of Canadians with Disabilities, 2010).

In 2009, the province of Ontario, Canada closed the last remaining government-operated institutions where people with ID lived, and very few institutions remain in other Canadian provinces. Since then, some people with ID have been successfully living on their own and are being supported by community services or non-profit organizations. One such Canadian organization is LiveWorkPlay, based in Ottawa, Ontario. LiveWorkPlay's mission is: "Helping the community welcome people with intellectual disabilities to live, work, and play as valued citizens" (LiveWorkPlay, n.d.). To support this mission, everyone involved with LiveWorkPlay works with a core value: "People with intellectual disabilities are valuable contributors to the diversity of our community and to the human family" (LiveWorkPlay, n.d.).

While the context in Canada differs from other countries, the deinstitutionalization movement has freed people with ID from confinement, but the problems are far from over because the multifaceted quest for autonomy involves living independently (Canadian Association for Community Living, 2011; Lenk, 2006), having access to paid work (Canadian Association for Community Living, 2011; Davidson, 2009b) and taking part in a society that has adopted digital technology and where much of the information is accessible online and much of the interactions happen online (Corona, Hannum, \& Davidson, 2014; Davidson, 2012).

Living autonomously commands several additional functionings, namely being able to sustain oneself in an economy where the cost of living constantly increases due to rapidly rising inflation, accessing goods online, being able to navigate governmental and paragovernmental services online through digital technology/mobile technology interfaces, and being able to engage in a workforce in which technology is pervasive. Unfortunately, people with ID do not have many positive role models to follow. In the current conjecture, people without ID create resources for people with ID to follow.

In order to address this multifaceted challenge, the imperatives of social justice require educators to develop new approaches in education with the population with ID. The primary objective of this study was to help people with ID to use mobile technologies to develop educational materials - that is self-advocacy videos that would allow them to share their authentic voice about the most significant accomplishments in their lives. A secondary objective was to study participants' authentic voices about the challenges and benefits that emerge when people with ID engage with mobile technologies while producing and sharing these videos.

\section{Literature Review}

This literature review provides an overview of the use of video-based interventions and the use of mobile technologies with people living with ID. The body of literature covers the use of digital technology to help people living with ID ranges from using specific devices to compensate for some sensory disabilities, to producing a variety of video-based interventions (VBI), to using technology as an aid to develop specific skills through a variety of pedagogical techniques. The literature we present covers VBI and mobile technologies for people with ID.

\subsection{Video-Based Interventions for People with ID}

When used in an educational context, video has been proven an effective tool to provide opportunities for learners who need to practice and repeat tasks before accomplishing them (Ogilvie, 2011). A substantial body of literature suggests that technologies can help improve learning for people who live with ID. Over the past decade, many researchers have studied the potential of video based intervention such as video prompting, video modeling, video self-modeling, computer-based video instruction and video priming, to help people with ID gain the autonomous and functional skills that they need to be fully integrated into society. These skills include, but are not limited to, making a purchase in a fast food restaurant (Mechling, Pridgen, \& Cronin, 2005), reading grocery aisle signs and locating items (Mechling, Gast, \& Langone, 2002), using public bus transportation (Mechling \& O'Brien, 2010), developing purchasing skills (Ayres, Langone, Boon, \& Norman, 2006), developing cooking skills (Mechling, Gast, \& Fields, 2008), developing cleaning skills (Cannella-Malone, Brooks, \& Tullis, 2013), developing employment skills (Goh, 2010; Mechling \& Ortega-Hurndon, 2007; Van Laarhoven, Johnson, Van Laarhoven-Myers, Grider, \& Grider, 2009), performing tasks with multiple steps (Mechling \& Ortega-Hurndon, 2007) and learning to use mobile technologies (Hammond, Whatley, Ayres, \& Gast, 2010).

In a review of empirical literature, Mechling (2008) points out that much of the research efforts using video have demonstrated that step-by-step instruction has a positive impact on the functional skills of people with ID. In addition, recent research has demonstrated that instructional video and video prompting tend to improve trainer behavior (Damen, Kef, Worm, Janssen, 
\& Schuengel, 2011; van Vonderen, Duker, \& Didden, 2010; van Vonderen, de Swart, \& Didden, 2010). Improving trainer behavior contributes to providing better pedagogical interventions for people with ID. Many of these researchers also suggest that as technology advances, it is becoming easier to use and more accessible, and people with ID are becoming more familiar with it. This is why VBI is considered such a sensible option when working with populations with ID.

Over the past decade, I have worked with populations with ID to help them speak up for themselves (Davidson, Leblanc, Leno, Clément, Godbout, Moldoveannu, Payeur, \& Turcotte, 2004; Leblanc, et al., 2008; Davidson, 2009a, 2009b) and develop what they call "selfadvocacy videos" (Corona et al., 2014; Davidson, 2009c; Davidson, Smith, \& Naffi Abou Khalil, 2011). Typically, these videos are co-created and co-edited and participants make their own decisions as to which message they want to send, what they want the video to look like and where they want it disseminated. In general, most participants like to have their video posted on YouTube, with the option to co-moderate the comments, and they share the hyperlink on their Facebook timeline. They like to show what they are capable of doing to their community and read comments that either show an appreciation for what they do or applaud them for providing an inspiring message for people with ID.

\subsection{Mobile Technologies for People with ID}

In the past five years, researchers have been interested in the use of mobile technologies with special and underserved populations. In 2010, the Rehabilitation Engineering Research Center on Communication Enhancement revealed that there is a need to conduct research that will explore the efficacy of mobile technologies such as iPods and iPads. At that time, many small-scale initiatives were being conducted in schools and with service providers, and there was a need to understand how to better use these technologies to help people living with ID.

Since then, many studies using mobile technologies with people with ID have been conducted worldwide. A systematic review conducted by an international team has identified fifteen studies using Apple products (iPods, iPads and iPhones) in teaching programs for people with ID (Kagohara et al., 2013). According to their analysis, the results are largely positive in terms of the potential of these technologies to help people with ID develop better communication skills, engage in leisure activities, and develop employment skills and life transitioning skills. Their systematic review concluded that these mobile devices are mostly used for two purposes: delivering instructions through video; and teaching people with ID to operate the devices.

One recent study concluded that using instructional videos in which participants with ID performed user- interface tasks helped them use iPods correctly (Hammond et al., 2010). Another study concluded that using iPhones to send video captions when participants were lost was an effective strategy to help them find their way back home (Purrazzella \& Mechling, 2013). Similarly, Kelley, Test and Cooke (2013) showed that the use of picture prompts with iPods for pedestrian navigation had a positive effect on travel route completion for people with ID (Kelley et al., 2013). A study has suggested that the combination of some forms of VBI, such as video modeling with iPods, has proven to be a useful strategy to teach communication skills (van der Meer et al., 2011) to people with ID. Another similar study has suggested that video modeling with audio and iPods was an effective tool to teach adults with ID to use automated teller machines (Scott, Collins, Knight, \& Kleinert, 2013). Notably, all of these studies focussed on the step-by-step approach to instruction and the classic approach to creating VBI for people with ID.

In one recent study I conducted with people with ID (Davidson, 2012), I used classic VBI, such as video prompting and video priming with iPods, to help participants develop functional and independent life skills. The videos were created in-house to meet the needs of the participants as stated by their intervenors, a process that I validated in an earlier study (Davidson et al., 2011). After using the videos for a period of ten weeks, I conducted a focus group during which most of the participants deemed the videos to be useful, and made suggestions for improvement. When I asked them in which of the areas of needs they would like to improve in the future, they were mostly interested in learning how to use the iPods for entertainment purposes instead of using the iPods to develop functional skills.

This is why some researchers invite caution when using mobile technologies (Arthanat, Curtin, \& Knotak, 2013; Selwyn, 2015) -they suggest evaluating mobile technologies critically before adopting them, and to avoid using them because they are trendy. Nonetheless, in the context of research with populations living with ID, Kagohara et al. (2013) mention that mobile devices have become socially accepted and they are less stigmatizing than traditional assistive technologies used by people with ID, which constitutes a good argument to exploit them with underserved populations.

One possible avenue to avoid the pitfalls related to using mobile technologies is to position the participants in the role of the producers of knowledge, rather than in the role of the consumers of knowledge. This partly justifies the underlying objectives of this study, which were to help people with ID produce educational resources in the format of self-advocacy videos in which they share their authentic voices about the most significant accomplishments in their lives, and to study how participants voice the challenges and benefits that emerge when people with ID engage with mobile technologies while producing and sharing these videos. 


\subsection{Capability Approach}

In this study, I adopted the Capability Approach pioneered by Sen (1992) and Nussbaum (2000). The Capability Approach focuses on what people can do rather than on their deficiencies. Developed by Amartya Sen (1992) and Martha Nussbaum (2000), the Capability Approach provides a valuable framework for thinking about pedagogical interventions and research with people with ID. This approach, which has been used in several research domains such as education, social sciences and psychology, is characterized as a framework by which we can "focus on what people are effectively able to do and to be" (Robeyns, 2005). This can be contrasted against both a "deficit model" which emphasizes the lacks from which people suffer, and a "social model" which tends to locate disability exclusively in the structure of the social environment (Terzi, 2005).

A central distinction in Sen's (1992) approach is between functionings and capabilities. Functionings, for Sen, are a fundamental category; they are the "beings and doings constitutive of a person's being" - examples of functionings would include being joyful (a being), or travelling to work on the bus (a doing) (Sen, 1992, p. 39). Capabilities, however, are individuals' potential to act in certain ways - in other words, capability is the power and freedom to enact functionings. The fundamental premise of Sen's Capability Approach is that, insofar as it is possible, one should aim toward the equalization of the capabilities of all individuals. This aim towards the equalization of capability applies equally to people living in poverty and to people with ID. Notably, the agenda for the development of capability should be chosen democratically in consultation with the people (e.g. people with ID) who are wishing to develop their capabilities (Terzi, 2005, p. 209).

This framework encompasses several central ideas about freedom of action and choice. According to the Capability Approach, having the possibility to choose what one can do as opposed to doing only what one can do is a fundamental freedom that we should focus on in studies on disability. This agency is difficult to develop since people with ID tend to face some challenges in converting resources-that is educational or material, into functionings. In the face of these challenges, the Capability Approach poses a normative question: How should educational resources be structured and delivered such that the capabilities of people with ID are equalized with others? In the case of people with ID, this equality of capability is a "regulative ideal" - we are not under the illusion that perfect equality in this regard is going to be brought about. Yet, insofar as it is possible to close the capability gap, it is worth working toward this outcome.

The study that I conducted was closely linked to the Capability Approach in a variety of ways. First and foremost, although I collected data about how people with ID engage with mobile technology, the study also aimed toward social transformation-specifically, it aimed to help people with ID develop and share their own capabilities. Second, in accordance with the democratic demands of the Capability Approach, participants identified relevant capabilities for development. The collaborative action research design, described in the next section, allowed participants both to identify relevant capabilities, and to develop those capabilities. Third, I rejected both the deficit model and the social model of disability. Although both of these models highlight the importance of the situation faced by people with ID, I worked with the premise that the most informative way to consider the situation was in terms of developing freedoms "to be" and "to do" with the help of mobile technologies, rather than merely locating deficits in the person or in the social environment and using VBI to help bridge the skills gap. The production of self-advocacy videos, in which people with ID speak up about successes in their lives with the help of tablets, was consistent with freedoms "to be" and "to do". Henceforth, because I adopted the Capability Approach with mobile technologies, it required a new approach to producing VBI for this study. Instead of analyzing participants' needs, identifying a knowledge base, breaking it down in steps, and packaging the information in the format of videos to be used to fill knowledge and skills gaps, I used iPads to let participants self-film, and engaged them in a collaborative video creation process.

\section{Methodology}

In keeping with the Capability Approach, the data were collected through a three-stage action research process during which participants used mobile technologies to produce self-advocacy videos to share their dreams and to speak about the accomplishments that were relevant to their situations. We recruited eight people living with ID for a purposive sampling. Two females and six males who strived to live on their own, secure paid employment or become integrated in the community were recruited through face-to-face events such as the LiveWorkPlay annual general meeting and through connecting online in social networking platforms. The participants recruited for this study were similar to participants I worked with in past studies and were representative of the population of people living with mild and moderate intellectual disabilities.

I used an iterative action research methodology, which was comprised of three steps: a planning phase, an action phase, and an evaluation/reflection phase. During the analysis/planning phase, I gathered preliminary data through informal interviews to help me identify what participants wanted to voice in their selfadvocacy videos. The purpose of this step was to work with participants to identify a set of capabilities they wished to discuss either because they were anticipat- 
ing the development of the underlying functionings or because they wanted to share their functionings to highlight their capabilities.

The action phase was two-fold. First, I showed participants how to self-film on iPads and they were able to make draft recordings to say whatever they wanted to share about their functionings. Second, we collaboratively produced self-advocacy videos using iPads according to the perspective the participant chose. I then validated the content with participants by viewing the videos with them and making necessary corrections. The decision to use iPads was informed by the fact that for a minimal investment, these tablets have embedded high definition camera lenses that provide 1080p full high definition video stabilisation, the native video editing software is effective, the transfer of video onto a laptop computer is easily done, and participants were not intimidated by the technology because it is so commonly used. Moreover, an iPad mounted on a tabletop tripod is not as invasive as a professional video camera mounted on a full-sized tripod.

To prepare for the evaluation/reflection phase, I published the videos on YouTube because this videosharing website features playback capabilities from any platform (Microsoft Windows, Apple operating system and Linux) in a good quality format (H.264), the settings can be public, unlisted or private according to the participants' decision, comments can be moderated before being posted, and videos can be embedded into Facebook, which was used by all our participants. I created a YouTube channel specifically designed for the study, which allowed me to share the videos with individual participants, and allowed them to use a private hyperlink to show it to people they trusted, which helped inform their decision about the privacy settings they wanted. This is how videos were disseminated through various channels that belong to the community of people living with ID, where people could contribute comments or read comments. I conducted a focus group with participants to ask them if they were satisfied with their self-advocacy videos, what their perception of the online comments were, and if they thought these videos could be used as pedagogical resources to help others either develop capabilities and underlying functioning or understand more of what they were capable. I considered it important to ask these questions during a focus group for several reasons: 1) participants would be able to view each other's videos collectively; 2) participants would benefit from hearing the testimonial of the person who was the co-producer of the video; 3) participants would be able to provide their reactions to the video, which consists of peer validation of the content; and 4) participants would be inspired by the accomplishments of others.

Elements of co-production were present throughout the three phases of this action research. During the analysis/planning phase, participants were entirely re- sponsible for the decision process about the topic of their videos. During the action phase, participants had time to experiment with self-filming using iPads and were given the opportunity to decide on the best approach to shoot their video footage. We watched the footage together and decided which segments were most important and how they might be presented to communicate the message efficiently. Video montages were completed in my laboratory and the participants were given YouTube hyperlinks for personal viewing, and for sharing with people they trusted if they wished to get another person's opinion. The people who had the hyperlink were able to post comments on YouTube, which provided a form of validation to the participants prior to the focus group where they received their peers' feedback. The participants were also able to make changes after the focus group, and to validate these changes prior to posting their final videos on YouTube.

\subsection{Description of Procedures and Data Analysis}

The data from the three phases were transcribed and analyzed using open-coding and axial coding, as suggested by Strauss and Corbin (1990), to find emergent themes. I used qualitative analysis software that allows coding and retrieving data directly from text and other sources of multimedia data such as video recordings, and I annotated the sequences of the video with particular verbatim.

The focus groups in the evaluation/reflection phase involved participants in data collection, and the analysis and interpretation of the data, a participatory approach suggested by Chevalier and Buckles (2009) that is congruent with the democratic emphasis of the Capability Approach. Such focus groups were deemed successful with this population several times (Davidson, 2009a, 2009b, 2010; 2012; Davidson et al., 2004; Davidson et al., 2011; Leblanc et al., 2008). One of the projects I conducted with participants from LiveWorkPlay has been identified as the only project of its kind in Canada by a group of researchers who published a meta-synthesis of action research involving people living with ID worldwide (Stack \& McDonald, 2014). According to Stack and McDonald (2014), very few projects of this kind are classified as high on the continuum of shared power, but they are worth conducting because "they reflect the value of including people with disabilities in matters that affect them and generate benefits for people with disabilities and for research" (p. 83).

Some participants wished to reveal their real identity, while other participants preferred to keep their anonymity, which is why some participants are referred to by their real name, while others are referred to with a participant number. To be consistent with the Capability Approach, which focuses on developing functioning, I deemed that the scope of the audience of the self-advocacy videos was not an issue. I considered 
that allowing participants to be self-advocates and talk about what they were able to do was a functioning worthy of mentioning without having to post it publicly. If the videos were posted publicly, it is because it is part of the culture at LiveWorkPlay to post participants' achievements. Some are posted within private networks, while others are posted publicly on their personal Facebook page. Some are featured in public events and in the media.

While the analysis shows what each participant has done individually for each phase of this action research, the focus group data were aggregated to present as a whole in order to protect the anonymity of participants who did not wish to be identified. The hyperlinks to videos are provided for only those participants who wished to reveal their identity. Again, to be consistent with the Capability Approach, I considered that being able to judge what could be posted publicly in social media, what should be kept private, and the varying degrees of public versus private life were important functionings that participants had to develop. While the study did not revolve around the issue of public versus private information, we discussed it at length to make sure participants understood the stakes and were able to make the decisions themselves. The LiveWorkPlay employees were helpful in that regard.

\section{Findings}

Findings are presented following the three steps of the action research I conducted. First, I examine the process of developing self-advocacy videos with mobile technologies using the Capability Approach in the planning phase. Second, I describe the action phase, which provides an analysis of the inventory of functionings and capabilities collected through the self-advocacy videos. Finally, I report on the data generated about the capabilities through the evaluation/reflection phase.

\subsection{Planning Phase: Initial Interviews}

The planning phase was done through initial interviews where I met with the participants to discuss functionings or capabilities they wanted to focus on in their videos. Most participants were excited to share a wide range of activities and events that were going on in their lives. The aggregated results of initial interviews are presented to give a sense of the wealth of functionings participants wished to share with the world and their capabilities in terms of political engagement, competitive sports, doing art and having paid jobs.

\subsubsection{Political Engagement}

Two of the eight participants were engaged politically in advocating for the rights and the needs of people with ID. Cooper was active in local/regional politics in trying to speak up for affordable housing in the city of Ottawa. He mentioned: "My number one [priority] is affordable housing. If there's a meeting with Paul Dewar or the City of Ottawa, I'm in for that for sure."

Participant 2 was active in local and provincial politics and she was involved in several self-advocacy movements including being President of People First [city], then being President of People First [province], being on the executive of the Disabled Women's Network, being a member of the [province] Council of Persons with Disabilities, and being on the Inclusive Design Committee of the Human Rights Museum in Manitoba. When I interviewed her, she was heading to a conference in Washington DC. She explained: "the purpose of the conference is based on the Article 19 of the UN Convention on the Rights of Persons with Disabilities on living in the community and there's going to be people from all over the world. I love to network with other people. I'm looking forward to networking with other people and stuff. The theme of the conference is Achieving Inclusion Across the Globe." During the interview, she mentioned that she had spoken in several academic contexts including the Global College at the University of Winnipeg, the Red River College in Winnipeg and the University of Manitoba. In addition, she revealed: "I co-authored a chapter in a book. I even had the privilege of being co-director of a movie!"

\subsubsection{Competitive Sports}

Three of the eight participants were competing in sports. During the initial interview, participant 5 mentioned: "I'm in Ottawa Special Olympics here, and I'm in swimming. Yes! And I'm in soccer also. Ottawa soccer team with Special Olympics." Competitive sports led him to travel for international competitions. He was proud to say: "We competed in Perth (England) this summer. Yes! We just did a bronze this year against the team I used to play on, yes." As far as his preferences go, he thought highly of both sports: "My favorite sport? I'm gonna say both [laughter]. It's hard to choose. Soccer is for summer and swimming is in the Fall-Winter sports."

Participant 3 was also involved in a competitive swimming team and he often travelled for competitions: "I've taken the bus trip to New Hampshire, the bus trip for the cruise. A long time ago, I went to Sand Piper by plane. The Nationals in Manitoba was by plane. Sometimes I take the bus to the Provincials. It's a coach, but this one I last went was by Via Rail, but there was a CP [Canadian Pacific] strike so I had to take the bus." While talking about his swimming schedule, he mentioned that he kept track of the details through online communication with the organizers of the swimming team and with his friends: "My friend just emailed me. If I click on this email, you can see that I emailed him. He did get my email. Next Friday there 
will be no cafeteria at the YMCA. It will be closed because of the holiday and that means that he and I are going to eat elsewhere before our workout."

Participant 1 mentioned receiving the Duke of Edinburgh's Award for a variety of physical accomplishments: "I did work for three years to get the award. I did physical like I did gym at the $\mathrm{Y}$, I did workouts, ran on the treadmill and it was a good experience and it helps you with your social skills and giving good to the community." When explaining his interest for physical activity, he stated: "I don't play sports. I kind of do, but like looking to try some sports just for a change. Like kickboxing. I'm looking to do some pursuit in that. I haven't tried it. Because...just for something new. A new physical challenge."

\subsubsection{Doing Art}

Two of the eight participants found pleasure in doing art. Caroline, who had a lot of experience with drawing and painting, volunteered in a senior home. She explained: "I was not teaching them, but I was just giving them company. I did flowers with them like paper flowers and I drew with someone else. Yeah I enjoyed their company. Yeah. We laughed and had fun." With regards to drawing, Caroline stated: "[I do art] quite often. I have these markers that I use. It relaxes me. [My ideas] just come up. I love colors. I didn't color that in yet." She mentioned she liked doing digital pictures on her phone: "Well, I do a drawing and I take a picture on my smartphone and I show people on Facebook the drawings." She showed me how she did it: "Open my phone. I go to my apps. I'll go on Facebook. I'm looking through my phone. I go into my pictures. I go to photo then it says upload, choose from gallery. I go there and I post it." When I asked what motivated her to post pictures on Facebook she responded: "It makes me feel good. It makes other people happy. They put 'Oh it's nice!' They put thumbs up. Things like that."

Participant 4 described similar sentiments with regards to his art: "It's fun. It's relaxing, you know. It gives you more energy. You relax doing a brush stroke. In Chinese brushing my art teacher is Heater McDonald." He explained: "I've been also doing art with Debra for fifteen years. I enjoy doing that 'cause I love doing it. She taught me good steps and wonderful steps and she's a wonderful artist. She teaches it."

\subsubsection{Having Paid Jobs}

Five of the eight participants had a paid job, which they thought was playing a very important function in having a fulfilling life. Cooper, Ryan, Participant 3, Participant 4 and Participant 5 all had paid jobs that they were very serious about. Participant 4 worked at the Canadian Mortgage Housing Corporation (CMHC): "I work for CMHC eighteen or seventeen years ago. I'm feeling really proud to go to work. Makes me happy again. I feel great about myself. I'm glad I'm returning to work on November 23rd. Where I work at CMHC, I do photocopies and I deliver the mail and I feel great about it. I could share one thing is that I'm really proud of my career award." Cooper worked in a credit card company's mailing room, but he was so busy with life that he didn't think it was such a big deal. He mentioned that work had been part of his routine for years and that it was something he could handle without any problem. As for Ryan, he was really happy to be employed at The Works. He explained: “I've worked in other places before, but this is the first job that they know about my disability and they accept me for who I am." Participant 5 also worked at The Works, but he had another job. He said: "I have two jobs. First I work at the Barrhaven Manor in Barrhaven and I'm housekeeping. It's a retirement home living. Yes. The Works is a gourmet burger joint in Barrhaven. I work there on Tuesdays and Thursdays. I've worked there since August 8th 2011." When I asked him how he felt about his two jobs, he declared: "I love my two jobs. They keep me busy. I've been working at the Manor on Monday, Wednesday, Friday and the other...before I went to The Works my days off were Tuesday and Thursday, so I had too much time on my hands at home resting so that's why I need to work - to keep busy." Participant 3 also worked at The Works. When talking about his job he said: "I really did a good job at my job at The Works. I did such a good job! They like having me there! I clean there. This is my third year. I've been getting really good at it." When I asked him why he liked it, he declared: "It has really good pay since you get to work overtime on public holidays. Also they help me with my music. They arrange music so I can get the work done quicker. They have something that's run by a computer satellite. Yeah because changing compact discs takes too long so they figured this playlist helps me get the work done faster."

From the participants' viewpoints there were so many exciting things happening in their lives that it was challenging for them to find the one capability that would be the focus of their self-advocacy video. The fact that these participants were already involved in a social integration process explains the variety of activities they were involved in. The capabilities they mentioned were intertwined with several functionings. The fact that all the capabilities that were mentioned by participants when thinking about self-advocacy videos fell into four categories, namely political engagement, competitive sports, doing art and having paid jobs, speaks to the importance of such functionings in their lives.

\subsection{Action Phase: Filming of Capabilities}

During the filming sessions, participants had to make a decision with regards to the focus of their video. They 
were aware that they would create the video footage with iPads. Some decided to self-film by putting the iPad on the table, but most didn't like the contreplongée viewpoint it created. They preferred to set up the iPad on a piece of furniture or a chair where they could either talk to it or film their profile as they did something, whether it was having a discussion with me or perfoming an action such as playing guitar or showing their art. Some participants asked me to hold the iPad and film them. The following section lists the selfadvocacy videos that participants created, and analyzes the underlying functionings and capabilities displayed by the participants.

Participant 1 wanted to do a video to talk about the Duke of Edingburgh Award that he had received. He self-filmed with the iPad and explained that he had worked hard to get this award and was proud of what he did, which seemed to be the main capability in his video: "I did workouts on the treadmill, I did community service..... It helps you with your social skills and giving good to the community." Participant 1 didn't have time to complete his video, but he sent us some pictures of the award ceremony to add to the video, which is a form of digital functioning.

We filmed the video with Participant 2 remotely through Skype, which didn't involve the use of an iPad on her part. She talked at length about her involvement in various organizations. She had just returned from a conference in Washington DC: "We arrived Wednesday night and then Thursday morning we started the conference and there was a pre-conference for self-advocates so there were over one hundred selfadvocates from thirty-five different countries across the world. I heard there were nine hundred people at the conference." She mentioned that, while at the conference, she had worked on a project and interviewed several people and hadn't been able to do much sightseeing. When talking about her political implication, Participant 2 explained: "A couple weeks ago, I got the privilege of meeting some MPs (Members of Parliament). About the cutbacks. The government cutbacks to the funding and about hiring people with intellectual disabilities."

When Participant 3 filmed his video, he had just moved into his new condominium and was excited to talk about his technological set-up and explain how he communicated with friends. To do his video, he asked someone to hold the iPad and film while he was talking. He explained how technology kept his home safe, how he used various websites to communicate with people, how he could fax documents directly to the Ontario Disability Support Program from his home, and how he connected a variety of devices for entertainment that could be remotely controlled.

Participant 4 talked about a variety of functionings in his video. In the first part of the video, he self-filmed with an iPad to talk about his work at the Canadian
Mortgage and Housing Corporation. He said: "I feel great about it!" He wanted to share the career award he had just received. In the first minute of the video, we see his index reaching for the home button on the iPad to turn the recording off, a segment he thought of removing, but he later decided to keep. This "recording mistake" informed his decision about setting-up the iPad on a different angle and discussing a different topic when Project Capabilities went to his house to continue the recording. He displayed all of his work around the house and spoke confidently about the various media he uses and about the fact that he sold some pieces. He said: "It gives more energy, you relax and you are doing the brushstroke." As an artist, he revealed his creative process, which starts from drawing a picture in his notebook and painting a matching scene. He said: "The story is that I started drawing this one [pointing at a picture of a sunset] and it matches this one [pointing at a painting]. This is part of my plan, I draw it first and then I paint it." When asked about the meaning of his art, he smiled, crossed his arms over his chest and declared: "It feels good to do it. It feels good inside to do it. Yeah, I really have a passion to do this."

In the beginning of his video, Participant 5 selffilmed with the iPad and talked about a variety of functionings. He stated: "I would like to show my guitar, and see how I've been playing." In the second part of the video, he placed two iPads, one for the profile and one frontal, so that he could show others how he played. At the end of the video he said: "I love playing guitar because my passion is music."

Cooper decided to create a two-part video: Part 1 covered independent living: https://www.youtube. com/watch?v=Vj38MK2DlcY; Part 2 covered community: https://www.youtube.com/watch?v=bDqnyUcQZDU. In the video about independent living, Cooper selffilmed with an iPad to talk about who he was and why he was able to live on his own. He explained that he loved staying active, but insisted on talking about more important issues such as affordable housing in the City of Ottawa. He clearly stated that the biggest problem was to get people out of their parents' houses and into their own apartments. He said: "A lot of people are scared of living on their own, but they shouldn't be scared of living on their own." In the first part, he clearly stated five independent living tips: 1) Plan your meals once a week; 2) Keep a calendar; 3) Keep a budget; 4) Use a cleaning schedule; and 5) Don't be afraid to ask for help! In the second part of his video, Cooper self-filmed with an iPad and insisted on the value of community: "Community? Being...being part of community means a lot to me. A lot to me and community means, like just being...being with everybody and not being on my own."

For Caroline, art was always central to her life. Her video was a montage of various footage that had been taken over years: https://www.youtube.com/watch?v= 
t5lluY55VU0. What she added was an explanation that she spent time with elderly people to draw with them. She said that she did this to keep them company. She also asked the interviewer to hold the iPad to film her while she showed the process she used to share the digital drawings she created on her mobile telephone and on her tablet with her social network.

Ryan invited us to his workplace and asked us to film him with the iPads: https://www.youtube.com/ watch?v=LevahXnP_4s. He spoke at length about his job: "I wanted to work at The Works actually and I saw they were opening one in Barrhaven. Matt and Joe came over to my house. He's an old job coach that we had and he came over and told me about The Works and there might be a position and he didn't want to tell me for sure just in case and then a few weeks later Jen called me and told me I had a job interview so I came here for the interview. I met with Dave and after I met with Dave we sat and talked and he gave me five days a week to start out with. I worked five days for a few months and then I found out that five is a little too much so I started working four days and then four was a little too much so I'm working three days and it's a great fit. I work three hours a day. From eight until eleven. Monday, Wednesday and Friday."

During the action phase, each participant had to find a way to create video footage about an important message they wanted to share. Given that they were sharing their capabilities naturally, without a written script, they had to find ways to be comfortable with the iPad as a recording device. Each participant asked for a treatment that made him or her feel comfortable. They spoke at length about their capabilities, which involved a variety of intertwined functionings. One participant insisted on participating remotely, because she felt comfortable with using Skype and because she lived far from Ottawa at the moment we conducted the study.

Notably, all participants focused on providing enough information about their capabilities and none was intimidated by the use of the technology. Another important salient point across participants is that while the capabilities they shared fell into various categories, namely receiving an award, being involved in various organizations, living independently, doing art, or having a paid job, there was nothing unusual about these capabilities compared to what brings life satisfaction to people living in the broader community. This is perhaps an indicator of how socially integrated the participants were. What was extraordinary, however, was how incredibly confident they felt about their capabilities.

\subsection{Evaluation/Reflection Phase: Focus Group and Online Comments}

During the focus group, participants saw the complete draft of their edited video. They were asked to com- ment about their own video and then the other participants were invited to join in a discussion. Five of the eight participants were present. Four participants were happy about their videos. One participant expressed his pride: "It's a video about living on my own. It's pretty good right?" Another participant was really enthusiastic about his video: "Well for me it's more interesting and hum...it's a really interesting story. My whole life, my own life. I've been through so much and that's why I love doing this and I have a passion for it and it feels great to do it....I don't want to change anything, it feels great!" A third participant said: "It feels pretty good to watch myself. I thought it was amazing." A fourth participant said: "It feels good. I think it's good."

When talking about Participant 3's video, one participant said: "I think it's cool that he has a fax machine. He can fax his own stuff." Another participant said: "The message is that he can live on his own. He can do his own things at home. Without his parents."

When talking about Ryan's video, one participant said: "I think it was good because it inspires me to get a job myself. It makes me feel like I won't give up. It makes me feel good and like to not give up on getting a job." Ryan responded: "And there's jobs out there!"

When talking about a video made by Participant 5, one participant said: "That's my favourite video! I like music too. I play the recorder...for fifteen years." Other participants said it was nice to hear him play his guitar.

While Cooper's video on independent living was playing, one participant declared: "That's powerful! You can do whatever you want. Just like Participant 4's video! Wow! That's a nice apartment or house." When asked for whom the message was powerful, the participant responded: "To the community. To us. To LiveWorkPlay." One participant added: "Well I was thinking more to people with disabilities. Or people that have been told they will never live on their own. This gives hope. And to do things. Like, I liked his calendar idea." Another participant approved: "Yeah his calendar idea was really great! It was a really good idea to keep a cleaning schedule." One participant explained: "It also gives you a powerful message like saying you can be on your own and not move in a residence, or not give up. Because sometimes I feel like giving up and going to a group home like where I have my own apartment, but I go for meals downstairs and stuff like that. But that gives a message that I can cook on my own."

Caroline criticized her video when she first saw it: "I made mistakes on it Ann-Louise. I don't talk loud. It's the way I talk. I don't know. I'm being silly maybe." When I turned the conversation to how others felt about the videos, everyone said they really liked the videos. When talking about Caroline's video, one participant said: "I think it's great!" Another participant said: "High five!" Caroline then explained her feelings: "I was disappointed that my video was not longer." She said she had more to offer, such as showing how she 
uses her tablet to draw. She was given the opportunity to film more footage and to add that part to her video. She was thrilled to do it and we spoke at length about what it should look like. The interviewer edited the video with her on the spot and she immediately shared it on Facebook.

In sum, the participants perceived the focus group as a celebration of their achievements. Most participants were happy to view their video publicly and to talk about why the video was important for them. Those who were less happy about their video simply wanted to improve the content to give a more powerful message-a more representative account of how well they were doing. The group conversation was inspiring in all perspectives: for each participant (who received a validation of their video by their peers), for the other participants (who were inspired by their peers' videos), and for the group (who felt that collectively, they were on the right track).

Following the discussion, the participants decided whether they wanted their videos to be public. The videos were posted on a YouTube channel and shared with the participants online. The reactions of the community to the videos were overwhelmingly positive: the videos created a feeling of pride and hope not only within the specific LiveWorkPlay community, but also within the broader community of people living with ID.

\section{Discussion}

In this study, I approached the production of educational materials for people with ID from a different perspective than that reported in the literature of video-based interventions. The Capability Approach I adopted, which aimed to document functionings and capabilities, put the participants in the role of coproducers of videos and producers of local knowledge structures emerging from their community and their residential integration process. On the one hand, participants had difficulty in deciding what to focus on in their videos because capabilities involve a lot of functionings and many functionings are important. On the other hand, the functionings participants revealed all had overarching capabilities they wished to share with the community:

- For Participant 1, obtaining an award was a culminating point that showed him that he could reach his objectives if he worked hard every day and didn't get discouraged.

- For Participant 2, who had a busy life filled with many activities, her capacity to be a self-advocate seemed the main capability she was proud of.

- For Participant 3, technology allowed him to be fully functional, to communicate with others and to entertain himself, which were all part of living on his own.
- For Participant 4, having a good life was doing things that brought him happiness.

- For Participant 5, there were many functional aspects of his life, but the one that made him feel better was his passion for music.

- For Cooper, a community was an enabler of independent living, and independent living was easier when someone lived in interdependence with the community.

- For Caroline, creating art made her feel good, but being able to show it to her friends through technology and get comments also created positive feelings and feelings of validation.

- For Ryan, the variety of functionings related to having a job were also related to being able to live on his own and pay his bills, which was connected to having a more fulfilling life.

My findings are in line with Sen's (1992) and Nussbaum's (2000) work on the Capability Approach because they show how choosing what one can do, instead of doing only what one can do, creates freedoms in the form of capabilities. Working with this framework means that one will look not only at a person's functioning (activities, achievements), but also at his/her freedoms in terms of capabilities. Co-producing these self-advocacy videos with people with ID would not have been possible if they had not been actively involved in a process of social and community integration. At the same time, these videos were enablers of more capabilities by helping participants realize what they had already accomplished (through the process of developing positive messages for others) and by allowing others to be inspired by what they had accomplished.

Creating videos with the Capability Approach in mind required a shift in terms of who was the producer of knowledge, which significantly distanced this study from the literature on VBI. The body of literature concerned with using VBI with people with ID and the researchers who have been producing and studying the impact of videos that are accessible on mobile technologies deserve a lot of merit. There is certainly a population that needs these types of studies about the development of functional skills, as pointed out by Ogilvie (2011), Mechling (2008), and Hammond et al. (2010). The results of this study shows, however, that when involved in a process of community and residential integration, people with ID are able to reveal their own functionings and capabilities, which helps generate positive feelings, and can serve as inspiration for others with ID.

Seeing oneself on a video sometimes causes selfconscious reactions such as not liking one's own appearance or not liking one's own voice. This is why collaboratively producing the videos and validating them with a group of peers were both important aspects of 
this study. Participants had a chance to see the footage and the edited videos and to re-do every step of the production if they were not satisfied. It was also comforting for the participants to know that their peers liked their video before they shared it online. Such collaboration in a shared power perspective did require more time and effort, but yielded better outcomes in terms of generating benefits for the community with ID.

With respect to the use of iPads, my findings align with several studies of people with ID that point to the potential of learning with mobile technologies (Kagohara et al., 2013). However, my findings differ from most studies because I used mobile technologies as a production tool instead of using them as a tool for delivering instructions or for learning to operate the device. The iPads were useful because they allowed the participants to take part in the production of the videos and to self-film, which was sometimes coupled with other footage. When participants self-filmed, I noticed that upon pressing the red button (the record button), they were ready to take a stand and speak up. This showed in the posture they adopted and in the fact that most of them took a deep breath before pressing the red button. iPads were used for this study because of their ease of use, but we could have used any other device with a front camera that allows self-filming.

\section{Conclusions}

This study revealed several benefits and challenges that emerge when people with ID engage with mobile technologies as co-producers of videos about the functionings and capabilities that underlie their community and residential integration process. There is no doubt that the three-step collaborative action research approach used in this study improved the relevance of the educational materials produced. The collective message that participants gave was clearly one of being able to lead satisfying lives and feel good about living, working and playing on a daily basis. Their other message was that when they see their peers succeed, it inspires them. One way of achieving this was through seeing self-advocacy videos related to functionings and capabilities created by their peers. This study provided insight into an innovative action research methodology that helped people with ID become self-advocates and take control of the messages they wanted to give by producing their own resources. With powerful mobile technologies so readily available and accessible, people with ID can and should produce their own educational resources.

\section{Acknowledgements}

I wish to thank LiveWorkPlay, the participants and the research assistants who worked on this project.

\section{Conflict of Interests}

The author declares no conflict of interests.

\section{References}

Arthanat, S., Curtin, C., \& Knotak, D. (2013). Comparative observations of learning engagement by students with developmental disabilities using an iPad and computer: A pilot study. Assistive Technology, 25, 204-213.

Ayres, K., Langone, J., Boon, R., \& Norman, A. (2006). Computer-based instruction for purchasing skills. $E d$ ucation and Training in Developmental Disabilities, 41(3), 253-263.

Boulanger, J., Wieszmann, S, Wolbert, V. (2010). The freedom tour documentary: An experiment in inclusive filmaking. In D. Driedger (Ed.), Living the edges. Toronto: Inanna Publications.

Brown, I., \& Percy, M. (2007). A comprehensive guide to intellectual and develop: Mental disabilities. Baltimore: Paul H. Brookes Publishing.

Canadian Association for Community Living. (2011). Inclusion of Canadians with intellectual disabilities. A national report card. Retrieved 01/18, 2012, from http://www.peiacl.ca/pdf/2011/CACL_Report_Card_ 2010_ENG.pdf

Cannella-Malone, H. I., Brooks, D. G., \& Tullis, C. A. (2013). Using self-directed video prompting to teach students with intellectual disabilities. Journal of Behavioral Education, 22, 169-189.

Chevalier, J., \& Buckles, D. (2009). SAS². A guide to collaborative inquiry and social engagement. Los Angeles: Sage Publications. Retrieved from http://www. idrc.ca/en/ev-130303-201-1-DO_TOPIC.html

Corona, S., Hannum, C., \& Davidson, A.-L. (2014). Project capabilities and adults with intellectual disabilities: Towards effective interviewing for a better social participation. Learning Landscapes, 7(2), 115-123.

Council of Canadians with Disabilities. (2010). Canada ratifies United Nations Convention on the rights of persons with disabiliites. Retrieved from http:// www.ccdonline.ca/en/international/un/canada/crpd -pressrelease

Damen, S., Kef, S., Worm, M., Janssen, M. J., \& Schuengel, C. (2011). Effects of video-feedback interaction training for professional caregivers of children and adults with visual and intellectual disabilities. Journal of Intellectual Disability Research, 55(6), 581-595. doi:10.1111/j.1365-2788.2011.01414.x

Davidson, A.-L. (2009a). Why is it so hard to talk about our intellectual disability? A pilot study using action research. Journal on Developmental Disabilities, 15(1), 8-20. Retrieved from http://oadd.org/index. php?page $=589$

Davidson, A.-L. (2009b). Community and residential integration, and paid employment go hand-in-hand: A 
collaborative inquiry. Journal on Developmental Disabilities, 15(2), 27-37. Retrieved from http://oadd. org/index.php?page $=619$

Davidson, A.-L. (2009c). Producing self-advocacy videos through a process of collaborative action research with adults living with an intellectual disability. International Journal of Learning, 16(9), 687-698.

Davidson, A.-L. (2010). Vid-Ability: A portable computing project to improve the condition of people living with an intellectual disability. In J. Herrington \& C. Montgomerie (Eds.), Proceedings of EdMedia: World Conference on Educational Media and Technology 2010 (pp. 3576-3581). Waynseville: Association for the Advancement of Computing in Education (AACE).

Davidson, A.-L. (2012). Use of mobile technologies by young adults living with an intellectual disability: A collaborative action research study. Journal on Developmental Disability, 18(3), 21-32. Retrieved from http://www.oadd.org/docs/41013_JoDD_18-3_2132_Davidson.pdf

Davidson, A.-L., Leblanc, R., Leno, S., Clément, N., Godbout, S., Moldoveannu, M.,..., Turcotte, C. (2004). Le projet "On Our Own Together II": À l'aube d'une ère nouvelle. Revue francophone de déficience intellectuelle, 15(2), 235-245.

Davidson, A.-L., Smith, J. C., \& Naffi Abou Khalil, N. (2011). Producing instructional videos through collaborative-action research for people living with an intellectual disability. In T. Bastiaens \& M. Ebner (Eds.), Proceedings of EdMedia: World Conference on Educational Media and Technology 2011 (pp. 15041509). Waynseville: Association for the Advancement of Computing in Education (AACE).

Goh, A. E. (2010). Video self-modeling: A job skills intervention with individuals with intellectual disabilities in employment settings (PhD Dissertation). Retrieved from Proquest.

Hammond, D. L., Whatley, A. D., Ayres, K. M., \& Gast, D. L. (2010). Effectiveness of video modeling to teach "iPod" use to students with moderate intellectual disabilities. Education and Training in Autism and Developmental Disabilities, 45(4), 525-538.

Kagohara, D. M., van der Meer, L., Ramdoss, S., O’Reilly, M., Lancioni, G. E., Davis, T. N., Rispoli, M., Lang, R., Marschik, P. B., Sutherland, D., Green, V. A., \& Sigafoos, J. (2013). Using iPods ${ }^{\circledR}$ and iPads ${ }^{\circledR}$ in teaching programs for individuals with developmental disabilities: A systematic review. Research in Developmental Disabilities, 34(1), 147-156.

Kelley, K., Test, D., \& Cooke, N. (2013) Effects of picture prompts delivered by a video iPod on pedestrian navigation. Exceptional Children, 79(4), 459-477.

Leblanc, R., Paruthi, R., Davidson, A.-L., Clément, N., Godbout, S., Leno, S.,...,Turcotte, C. (2008). The "on our own together housing project" (cooperative housing for people with intellectual disabilities). Journal on Developmental Disabilities, 14(3), 74-85.
Lenk, A. (2006). Housing for adults with intellectual disabilities (No. 65012). Canada: Canada Mortgage and House Corporation.

LiveWorkPlay. (n.d.). Website. Retrieved from www. liveworkplay.ca

Mechling, L. (2008). High tech cooking: A literature review of evolving technologies for teaching a functional skill. Education and Training in Developmental Disabilities, 43(4), 474-485.

Mechling, L. C., Gast, D., \& Fields, E. (2008). Evaluation of a portable DVD player and system of least prompts to self-prompt cooking task completion by young adults with moderate intellectual disabilities. Journal of Special Education, 42(3), 179-190.

Mechling, L. C., Gast, D. L., \& Langone, J. (2002). Computer-based video instruction to teach persons with moderate intellectual disabilities to read grocery aisle signs and locate items. Journal of Special Education, 35, 224-240.

Mechling, L. C., \& O’Brien, E. (2010). Computer-based video instruction to teach students with intellectual disabilities to use public bus transportation. Education and Training in Developmental Disabilities, 45, 230-241.

Mechling, L. C., \& Ortega-Hurndon, F. (2007). Computerbased video instruction to teach young adults with moderate intellectual disabilities to perform multiple step, job tasks in a generalized setting. Education and Training in Developmental Disabilities, 42, 24-37.

Mechling, L. C., Pridgen, L., \& Cronin, B. (2005). Computer-based video instruction to teach students with intellectual disabilities to verbally respond to questions and make purchases in fast food restaurants. Education and Training in Developmental Disabilities, 40, 47-59.

Memari, A. H., \& Hafizi, S. (2015). People with intellectual disability and social-political life participation: A commitment to inclusive policies in less developed countries. Journal of Policy and Practice in Intellectual Disabilities, 1, 37-41.

Nussbaum, M. C. (2000). Women and human development: The capabilities approach. Cambridge: Cambridge University Press.

Ogilvie, C. R. (2011). Step by step social skills instruction for students with autism spectrum disorder using video models and peer mentors. Teaching Exceptional Children, 43(6), 20-26.

Purrazzella, K., \& Mechling, L. C. (2013). Use of an iPhone 4 with video features to assist location of students with moderate intellectual disability when lost in community settings. Education and Training in Autism and Developmental Disabilities, 48, 179-189.

Robeyns, I. (2005). The capability approach: A theoretical survey. Journal of Human Development, 6(1), 93114.

Scott, R., Collins, B., Knight, V., \& Kleinert, H. (2013). Teaching adults with moderate intellectual disabili- 
ties ATM use via the iPod. Education and Training in Autism and Other Developmental Disabilities, 48, 190-199.

Selwyn, N. (2015). Minding our language: Why education and technology is full of bullshit...and what might be done about it. Learning, Media and Technology, 1-16. doi:10.1080/17439884.2015.1056190

Sen, A. (1992). Inequality reexamined. Oxford: Oxford University Press.

Stack, E., \& McDonald, K. (2014). Nothing about us without us: Does action research in developmental disabilities research measure up? Journal of Policy and Practice in Intellectual Disabilities, 11(2), 83-91.

Strauss, A., \& Corbin, J. (1990). Basics of qualitative research. Techniques and procedures for developing grounded theory. Newbury Park, CA: Sage.

Terzi, L. (2005). A capability perspective on impairment, disability and special educational needs: Towards social justice in education Theory and Research in Education, 3(2), 197-223.

United Nations. (2006). Convention on the rights of persons with disabilities. UN Web Services Section, Depart of Public Information. Retrieved from http:// www.un.org/disabilities/convention/conventionfull.s html van der Meer, L., Kagohara, D. M., Achmadi, D., Green, V. A., Herrington, C., Sigafoos, J.,...,Rispoli, M. (2011). Teaching functional use of an iPod-based speechgenerating device to individuals with developmental disabilities. Journal of Special Education Technology, 26, 1-11.

Van Laarhoven, T., Johnson, J. W., Van Laarhoven-Myers, T., Grider, K. L., \& Grider, K. M. (2009). The effectiveness of using a video iPod as a prompting device in employment settings. Journal of Behavioral Education, 18, 119-141. doi:10.1007/s10864-009-9077-6

van Vonderen A, de Swart C, \& Didden R. (2010). Effectiveness of instruction and video feedback on staff's use of prompts and children's adaptive responses during one-to-one training in children with severe to profound intellectual disability. Research in Developmental Disabilities, 31(3), 829-838.

van Vonderen, A., Duker, P., \& Didden, R. (2010). Instruction and video feedback to improve staff's trainer behaviour and response prompting during one-to-one training with young children with severe intellectual disability. Research in Developmental Disabilities, 31(6), 1481-1490. doi:10.1016/j.ridd. 2010.06.009

\section{About the Author}

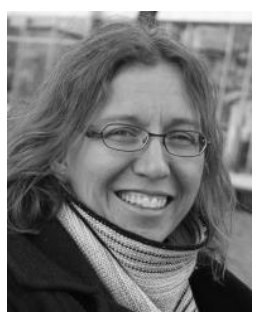

Dr. Ann-Louise Davidson

Ann-Louise Davidson is an Associate Professor of Education at Concordia University where she teaches in the Educational Technology graduate program. Her research interests revolve around the changes brought by digital technologies in society and in the educational system, and their impact on how human beings learn individually and socially. She studies the impact of digital technologies on the social integration of minorities and marginalized populations. 